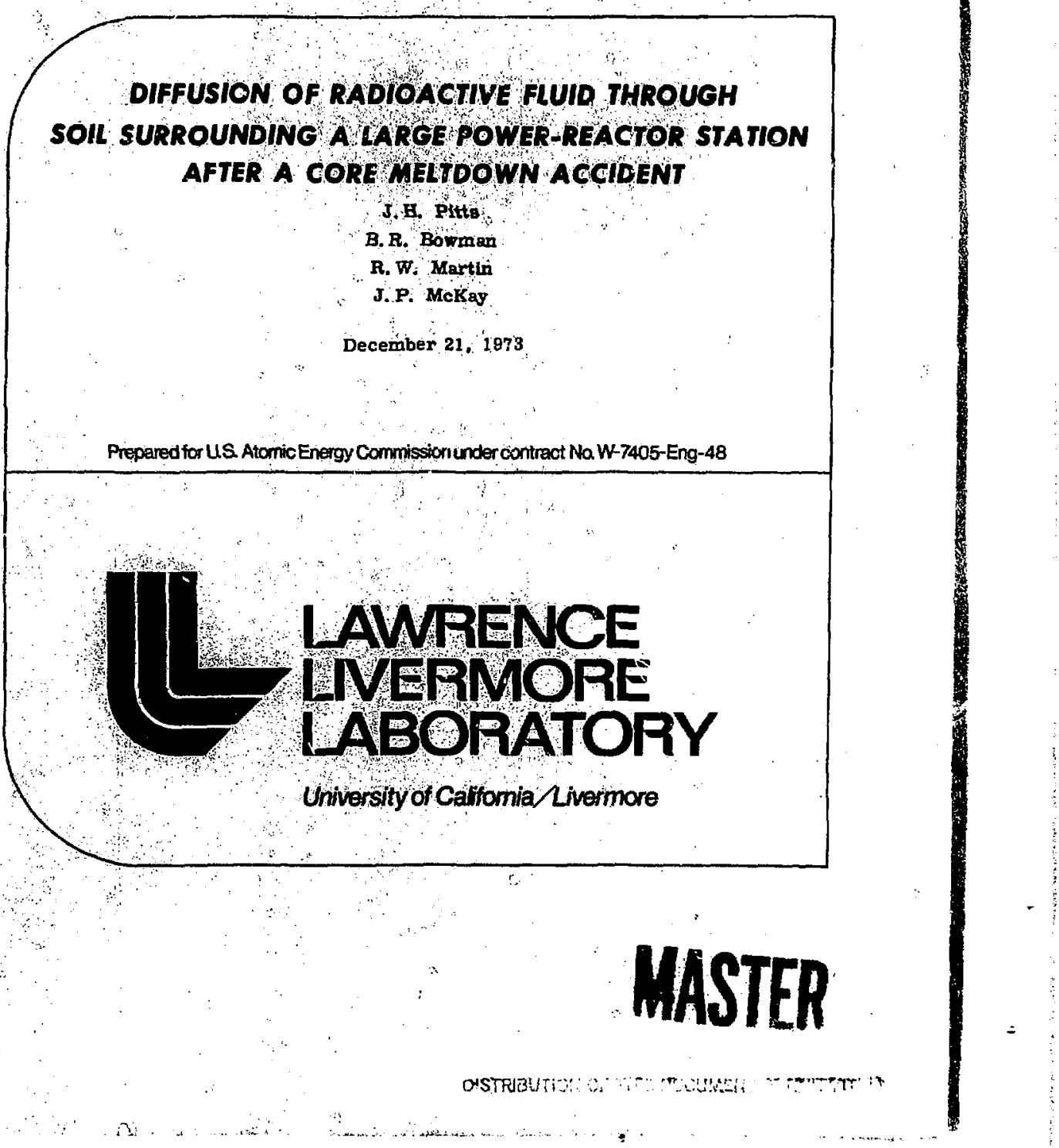


$T[D-4500, U C-B 0$

General Reactor

Technology

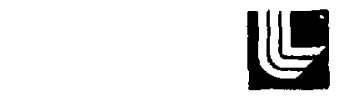

LAWRENCE LVERMOPE LABOAATOFY

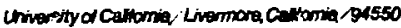

UCRL -51494

\section{DIFFUSION OF RADIOACTIVE FLUID THROUGH \\ SOIL SURROUNDING A LARGE POWER-REACTOR STATION AFTER A CORE MELTDOWN ACCBDENT}

J. H. Pitts

B. R. Bowman

R. W. Martin

J. P. MeKay

MS. date: December 21, 1973

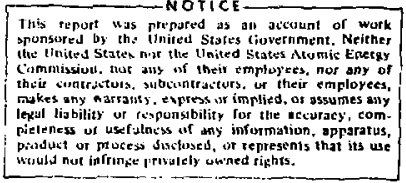




\section{Contents}

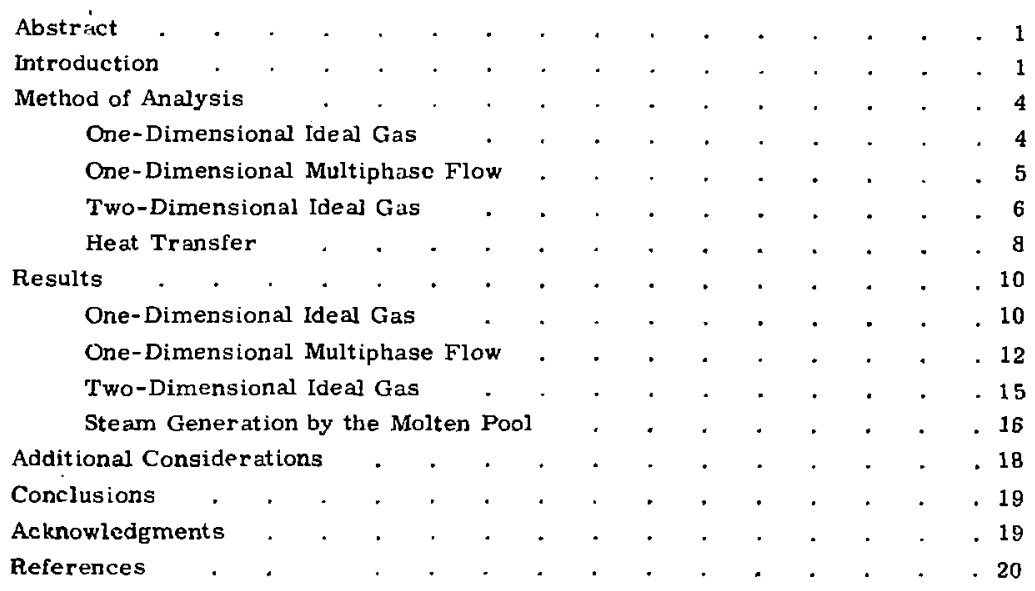




\title{
DIFFUSION OF RADIOACTIVE FLUID THROUGH SOIL SURROUNDING A LARGE POWER-REACTOR STATION AFTER A CORE MELTDOWN ACCIDENT
}

\begin{abstract}
The flow of fluids through the soil surrounding a large power-reactor station after c. core meltdown accident was analyzed. Fracture of, or penetration through, a portion of the containment floor was assumed so that radioactive gases would be driven through the soil by pressure within the containment shell.

Results for both one-dimensional ideal gas and multiphase flow were abtained using dimensionless variables so that results are applicable for all soil conditions. Two-dimensional results are i._._uded for a specific case where permeability of the soil varies spatially.

These calculations show that the time required for radioactive gases to permeate to the ground surface are years for silty-type clays and about $10 \mathrm{~h}$ for sand-type soil.

Hoat transfer calculations th at estimate the amount of steam generated should the core melt penetrate the containment floor and contact wet soil show that cooling systems must be in operation within four or five days in order to prevent overpressurization of the containment shell. Fluid motion existing in the region immediately around the containment shell and also caused by fissure propagation is mentioned.
\end{abstract}

\section{Introduction}

A reactor accident which causes core meltdown will probably never occur in a large power-reactor station. However, because the effects of such an unlikely accident could be serious, a study of conditiong following core meltdown should be included as part of any safety analysis report. Such studies are useiul in the design of future power stations. Also they help to minimize or eliminate adverse effects should an accident occur in an existing power plant.
We examined one means by which radioactive matter could reach the ground surface and be released into the atmosphere following a core meltdown accident. Consider that the melted core interacts with the containment foor so that either the molten pool penetrates the floor, or the floor is fractured to such an extent that it no longer can be considered as a containment barrier. Radioaciıve fluids would ther be released into the soil beneath the containment shell and permeate 

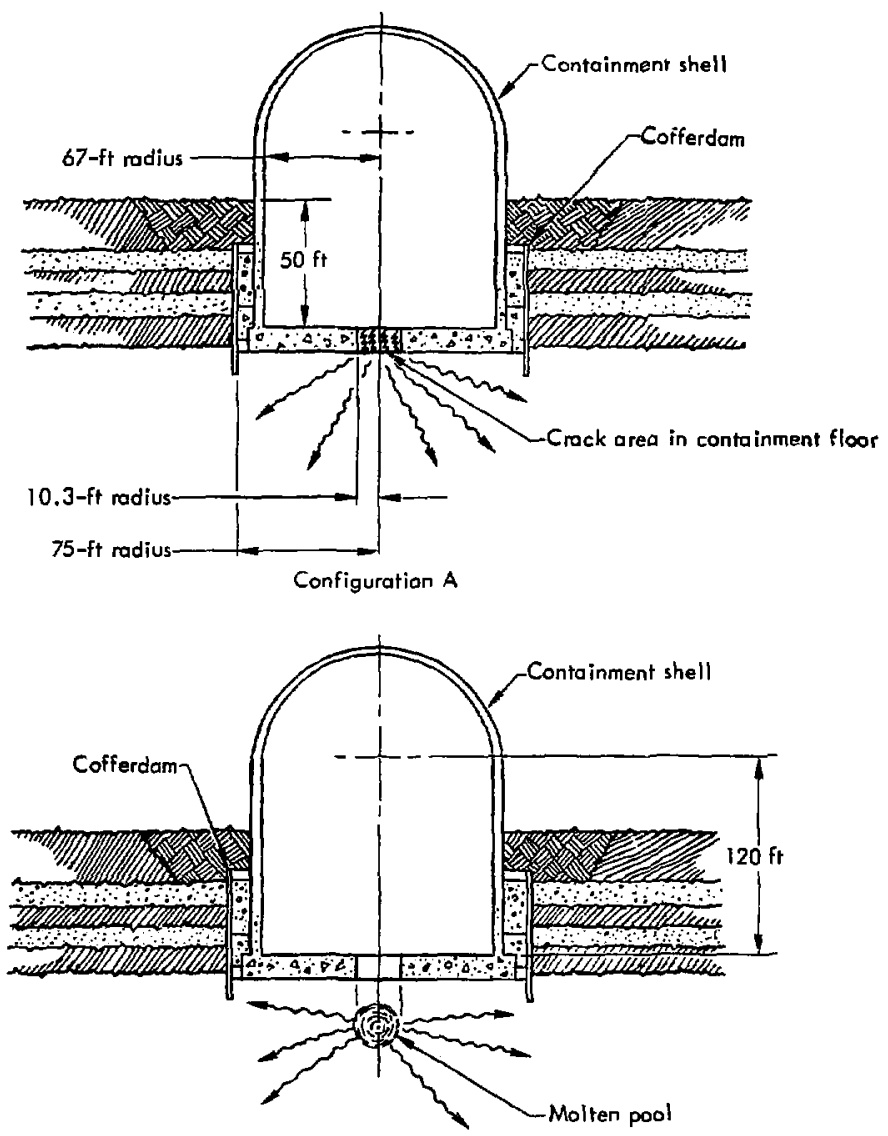

Configuration B

\begin{tabular}{|l|l|}
\hline \multicolumn{2}{|c|}{ Legend } \\
\hline 4 & Concrete \\
\hline 4 & Sand \\
\hline & Cloy \\
\hline
\end{tabular}

Fig. 1. Schematic of two possible configurations after a core meltdown accident in a large power-reactor station. 
in all directions through the soil (see Fig. 1). From a calculational standpoint, the analysis is approximately the same for both cases since active material is released by essentially the same point source. The driving pressure is that present in the containment shell. Changes in the concentration of radioactive matter due to filtering interaction with the soil or adsorption are not included.

We have completed a four-part analytical study that predicts the extent of penetration of radioactive fluid into the soii and possible release into the atmosphere using methods similar to those developed by Morrison. 1,3 The problem was first bounded using our onedimensional programs with a noncondensible gas. Geometries included applicable cases in Cartesian, cylindrical, and spheric al coordinates.

In the first study, we considered a Cartesian model of a constant-area column with a length equal to the distance from the expected source through the soil to the ground surface. Soil properties (e.g. permeability and porosity) were assumed constant. The results of this calculation are used as a bound on the timc for release of active gas to the atmosphere and for comparison with condensible fluid calculations described later. Use of dimensionlegsi parameters permits application of the results to numerous cases with different gases and having different soil properties. A model using cylindrical coordinates simulates possible radial flow of nonconjensible gases in a single layer of soil. For example, consider the earth ariund the reactor to consist of a horizontal layer of sand with clay above and below. The permeability in the sand region would be probably several orders of magnitude above that of the clay. Should gases reach this relatively high permeability region, vertical flow could be neglected in comparison to radial flow. Spherical coordinates may be used to determine the extent of flow below the containment floor shown in Fig. 1. This model is accurate until a pressure response is felt at the outer radius of the cofferdam. Beyond this time, gases would be able to permeate both ertically toward the ground surface and radially outward in a two-dimensional fashion. If the outer $r$ adius of the one-dimensional sph-rical coordinate problem is taken equal to the sum of the distance from the source to the outer cofferdam radius and the vertical distance to the ground surface, the predicted time of arrival would be shorter than that actually occurring.

A second set of calculations using our one-dimensional, Cartesian coordinate, multiphase flow model was completed so that effects of steam condensing within the pores of the soil could be included. In all calculations, a mass balance $w$ as maintained so that the pressure within the containment shell decreased as flow into the soil occurred. We found that this pressure decay due to flow out of the containment shell was small for most cases. (A more rapid decay would occur if the permeability was high or if the gas source volume was reduced in size.) As a result, we also studied effects at a constant containment shell pressure since this permitted further generalization of resuits and the use of similarity solutions.

The third part of the study utilized Bowman's ${ }^{3}$ two-dimensional extension of the noncondensible program. This 
permitted us to closely model the geometry of the containment shell shown in Fig. 1 , and to include various layers of soil, each with appropriate properties. The extent of radioactive gas penetration with time for condensible flow may be estimated by comparisou of changes found for a noncondensible gas on a one-dimensional basis.

The fourth and last series of calculatious was aimed at bounding the extent of heat dissipation from the outer yall of the containment shell and the steam generation caused by contact of the core melt with surrounding ground water should the molten pool penetrate the containment foor. These results were used to justify the use of a constant pressure $(25,50$, or 100 psia) inside the containment shell. The last two values correspond to what might be the design pressure and rupture pressure of the containment sbell.

\section{Method of Analysis}

\section{ONE-DIMENSIONAL IDEAL GAS}

In the first part of the study we considered one-dimensional, isothermal flow of an ideal gas. The restriction of isothermal flow is reasonable since the heat capacity of the soil is much larger than the energy present in the gas flowing through the pores of the soil. The continuity equation for compressible now through porous media with constant porosity may be written as

$$
\nabla \cdot(\rho \overrightarrow{\mathrm{u}})+\epsilon \frac{\partial \rho}{\partial t}=0,
$$

where $\rho$ is the fluid density, $\epsilon$ is the porosity, $t$ is time, and $\vec{u}$ is an apparent velocity equal to the volume flow rate per unit area normal to the now.

Conservation of momentum is satisfied using Darcy's Law 4

$$
\ddot{\mathbf{u}}=-\frac{\mathbf{k}}{\mu} \nabla_{\mathrm{p}},
$$

which is a constitutive equation for lowReynolds-number flow through porous media. Here $p$ is the pressure in the
Fuid, $\mu$ is the firlit viscosity, and $k$ is the permeability of the solid. Using an ideal gas equation of state

$$
p=\rho R T \text {, }
$$

where $R$ is the gas constant and $T$ is the fluid temperatis? which we take to be constant, the governing equation becomes

$r^{1-n} \frac{\partial}{\partial r}\left(r^{n-1} p \frac{\partial p}{\partial r}\right)=\frac{\epsilon \mu}{k} \frac{\partial p}{\partial t}$,

where $\mathbf{r}$ is the spatial variable and $n$ is set equal to 1 for Cartesian coordinates, 2 for cylindrical coordinates, and 3 for spherical coordinates.

Equation (4) is placed in dimensionless form by defining

$$
\mathrm{x}=\frac{\mathbf{r}}{\mathbf{R}_{0}} \text {. }
$$

where $R_{0}$ is the outer radius of the porous medium,

$$
F^{\prime}=\frac{p-p_{0}}{p_{1}-\frac{p_{0}}{p_{0}}},
$$

where $P_{1 j}$ is the initial nuid pressure in the pores of the solid and $P_{1}$ is the initial doiving pressure and 


$$
\tau=\frac{k\left(p_{1}-p_{0}\right)}{\epsilon \mu R_{0}^{2}} t,
$$

where $\tau$ is dimensionless time and

$$
N=p_{1} / p_{0} .
$$

In terms of these dimensionless quantities, Eq. (4) becomes

$$
\begin{aligned}
& \frac{\partial^{2}}{\partial X^{2}}\left(P^{2}+\frac{2 P}{N-1}\right) \\
& \quad+\frac{n-1}{X} \frac{\partial}{\partial X}\left(P^{2}+\frac{2 P}{N-1}\right)=2 \frac{\partial P}{\partial T} .
\end{aligned}
$$

Boundary conditions used are:

$$
\begin{aligned}
& P=0 \text { at } \tau=0 \\
& P=0 \text { at } X=1 \text { for all } \tau \\
& P=1 \text { at } X=X_{0} \text { at } \tau>0 .
\end{aligned}
$$

The value $x_{0}$ is the ratio of inner to outer radius and is set equal to zero if Cartesian coordinates are used. A time-dependent driving pressure at $\mathrm{X}=\mathrm{X}_{0}$, instead of a constant value, may be incorporated if desired. The time dependency of pressure decay may be calculated to correspond to the mass flow rate into the porous media or any other mathematical relationship.

If we define a dimensionless mass

$$
\mathbf{M}=\frac{\mathbf{m}}{\mathbf{m}_{0}},
$$

where $m$ is the total mass that has left the outer radius of the solid, and $\mathrm{m}_{0}$ is the mass of gas originally in the pores of the solid, we may write the continuity relation where $A$ is the flow area as

$$
\frac{d M}{d t}=\frac{d\left(m / m_{0}\right)}{d t}=\frac{\rho \overrightarrow{u A}}{m_{0}} .
$$

When combined with Darcy's law and the definitions of dimensionless parameters, this becomes

$$
\begin{aligned}
& \frac{d M}{d T}=-\frac{n}{\left(1-X_{o}\right)^{n}} \frac{N-1}{3} \\
& \quad \quad \times\left.\frac{d}{d X}\left(P^{2}+\frac{2 P}{X-1}\right)\right|_{X=1}
\end{aligned}
$$

The total mass having left the porous solid is

$$
\begin{aligned}
M= & -\frac{n}{\left(1-X_{0}\right)^{n}} \frac{N-1}{2} \\
& \left.x \int_{0}^{T} \frac{d}{d X}\left(P^{2}+\frac{2 P}{N-1}\right)\right|_{X=1} d \tau .
\end{aligned}
$$

When $M$ equals unity, the mass having left the solid will just equal the original mass of gas in the pores, Gats originally in the containment shell would start to be released at this time.

Equation (9) is solved using a rinite difference technique with Eqs. (12) and (13) used to determine the rate add amount of mass that has left the solid. lise of dimensionless parameters is very advantageous since it makes the results applicable for all values of permeability, porosity, and gas viscos ty.

\section{ONE-DIMENSIONAL MULTIPHASE FLOW:}

In the second series of calculations we considered one-dimensional flow of steam and air in a Cartesian-coordinate system. Even though pure steam was considered to be injected into the soil, air or other noncondensible gases are present under ambient conditions in the pores of the solid so that the solution must consider two species as well as two phases. For 
each species we write a continuity equation of the form

$$
\frac{\partial}{\partial x}(\rho u)+\epsilon \frac{\partial}{\partial t}(\rho S)=0,
$$

where $S$ is the saturation of the species or the fraction of the pore volume accessible to the component species. If $\ell$ represents liquid water, $m$ the mixture of air and water vapor, a the noncondensible air alone, and $v$ the water vapor alone; we may write the two necessary continuity equations as

$\frac{\partial}{\partial x}\left(\rho_{a} u_{m}\right)+\epsilon \frac{\partial}{\partial t}\left(\rho_{a} S_{m}\right)=0$ (air)

and

$$
\begin{aligned}
\frac{\partial}{\partial x}\left(\rho_{\ell} u_{l}\right. & \left.+\rho_{v} u_{m}\right) \\
& +\epsilon \frac{\partial}{\partial t}\left(\rho_{l} S_{\ell}+\rho_{v} S_{m}\right) \\
& =0\left(H_{2} O \text { liquid and vapor }\right) .
\end{aligned}
$$

All species in gaseous phase are assumed to move at the velocity of the gaseous mixture. Each phase obeys Darcy's law with a relative perinability included to account for $r$ the interaction of the two phases;

$$
\begin{aligned}
& u_{l}=-\frac{k}{\mu_{l}} k_{c l} \frac{\partial p}{\partial x}, \\
& u_{m}=-\frac{k}{\mu_{m}} k_{r m} \frac{\partial p}{\partial x} .
\end{aligned}
$$

The relative permeabilities, $k_{r \ell}$ and $k_{r m}$. are taken to be functions of water saturation in the pores of the solid and are the ratio of effective permeability of a phase to the absolute permeability of the solid.

For an elemental volume of the column the energy equation is written as

$$
\begin{aligned}
& \frac{\partial}{\partial x}\left(\rho_{l} u_{l} h_{l}+\rho_{v} u_{m} h_{v}+\rho_{a} u_{m} h_{a}\right) \\
& +\epsilon \frac{\partial}{\partial t}\left(\rho_{l} s_{\ell} e_{l}+\rho_{v} s_{m} e_{v}+\rho_{a} s_{m} e_{a}\right) \\
& +(1-\epsilon) \rho_{s} \frac{\partial e_{s}}{\partial t}=0 .(19)
\end{aligned}
$$

where $h$ is enthalpy and $e$ is internal energy. Equations (15) through (19) are combined using dimensionless variables as shown in Ref. 2 with equations of state for steam, water, vapor, and air, and then solved using finite difference techniques. By neglecting gravitational effects and axial heat conduction, and considering a semi-infinite medium, a similarity solution exists where water saturation, pressure, and temperature may be determined as a function of the similarity variable, $\theta$, where

$$
\theta=\frac{x}{\overrightarrow{2}} \sqrt{\frac{\epsilon \mu_{a}}{k p_{1}^{t}}} .
$$

\section{TWO-DIMENSIONAL IDEAL GAS}

A third set of calculations modeled the geometry of a typical, large, power reactor in a two-dimensional ideal gas calculation (see Fig. 2). We used the equations of the one-dimensional ideai gas calculation and extended them to two dimensions. That is, the transient flow is governed by Eqs. (1) through (3) except that now the permeability takes on the form of a tensor. The equations ire solved for the pressure in cylindrical coordinates using an explicit, finite-difference approximation with a constant temperature.

Variations of soil peri. hility between layers of sand and clay are permitted as shown in Fig. 2. The permeability is 


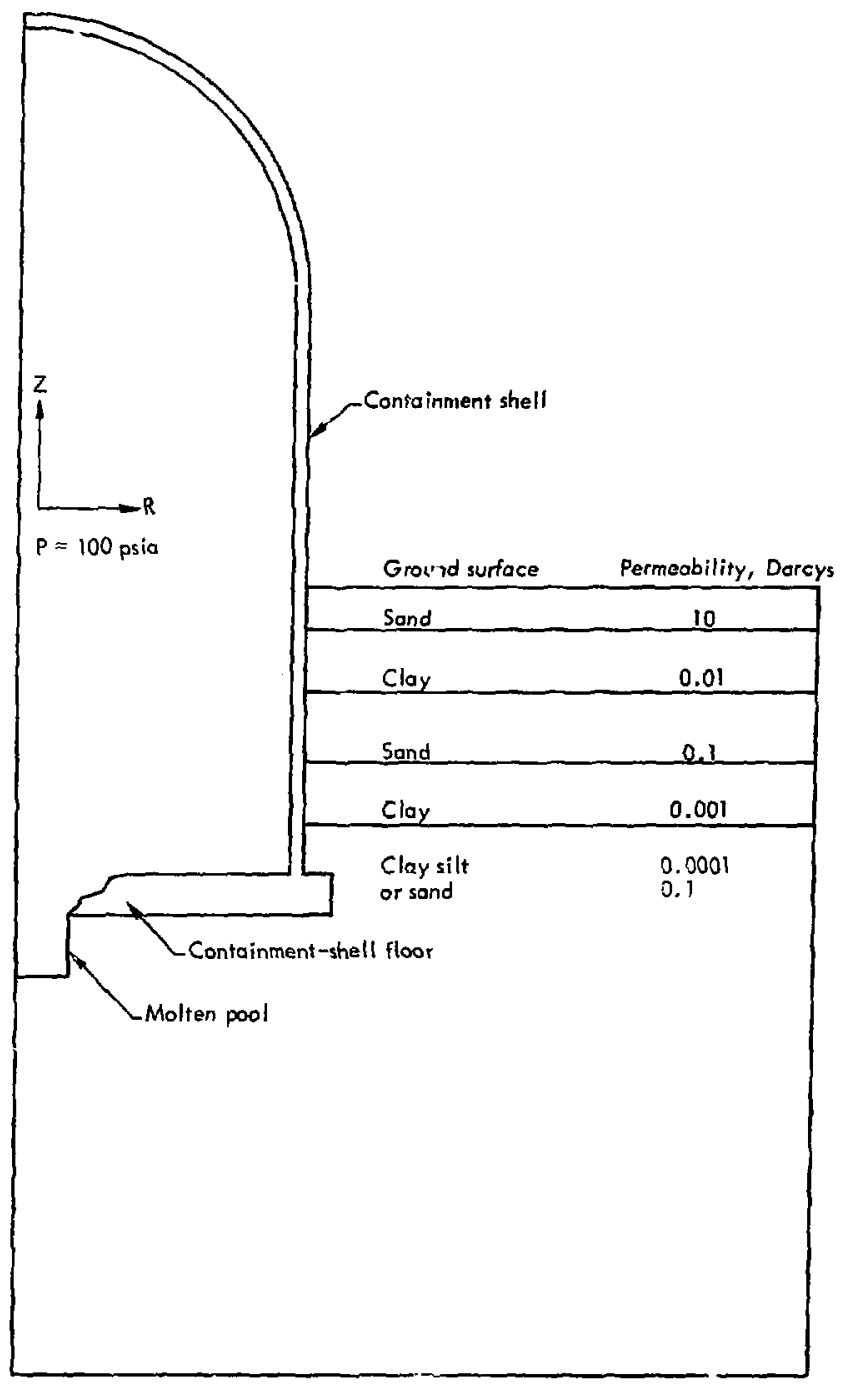

Fig. 2. Configuration for the two-dimensional, single-phase calculation in cylindrical coordinates. 
assumed to be isotropic within each soil layer and does not vary with time. Porosity values are typical for the gas-filled porosity in alluvial clays and sand. ${ }^{5}$ This porosity represents the fraction of interconnected void volume available for flow of gas in the porous media. It is assumed that the only effect of liquid in the pores is to reduce the porosity.

Pressure within the containment shell is assumed to decay with time as a result of mass flow from the shell into the surrounding soil; however, this decay was again found to be small except for cases of reduced gas source volume or high soil permeability. The containment shell is assumed to be impermeable except for a 10.3-ft-radius cylinder representing the volume occupied by the risss of the molten core.

\section{HEAT TRANSFER}

We estimated the dissipation of heat generated after core meltrlown by considering conduction through the containmentshell wall. If the core does not penetrate the containment floor and all cooling systems are inoperative, a simple heat balance may be used to estimate the inside surface temperature of the containment shell. Taking an average he at generation rate of $3.5 \times 10^{7} \mathrm{Btu} / \mathrm{h}$ over the first $30 \mathrm{~h}$ after core meltdown, the temperature drop through a 2.5-ft-thick concrete contzinment shell exceeds $3000^{\circ} \mathrm{F}$. This temperature is in excess of what concrete will withstand. Without an operative cooling system or the addition of material whose heat capacity is very large, failure of the containment shell would be certain.
Should the core melt penetrate the containment floor, the energy generated would vaporize the v:ster present in the pores of the scil adjacent to the molten pool. We examined the problem of heat conduction in an infinite, homogeneous medium capable of undergoing phase change in order to determine the amount of steam which could be generated by the core uncer these conditions. T'he internal boundary was a sphere of 10.3 -ft radius with a constant internal neat generation rate of $3.5 \times 10^{7} \mathrm{Btu} / \mathrm{h}$ (see Fig. 3).

The solution followed the finite slement method of Wilson and Nickell. ${ }^{6}$ The molten pool was assumed to be statinnary and the thermal properties of the soll during phase change were taken to be an average of the saturated and dry conditions. Steam was assume: +o how from the soil into the containment shell with negligible pressure loss since any substantial buildup of pressure would fracture the soil.

The basic solution techniqio uses the matrix equations

$$
[K](\theta)=\langle Q\rangle
$$

with

$$
[K]=[K]+[C] .
$$

where $\kappa$ and $C$ are matri.zes which include the thermal conouctivity anc heat capacity, $\theta$ is the temperature difference vectcr, and $Q$ is a thermal force vector which includes heat flux across the element surface and interna! heat generation. The solution begins at time zero with given initial conditions, and proceeds until the average temperature of the first spherical shell of soil equals the saturation temperature specified. When saturation temperature is attained, the thermal 
properties of the soll in that shell are changed to those representing the avarage moisture condition during phase change and the appropriate thermal matrices are reevaluated. Whon the added energy is equal to that required to transform the water to steam, the phase change is ccimplete. Soil properties are then modified again to reflect the dry condition of the soil.

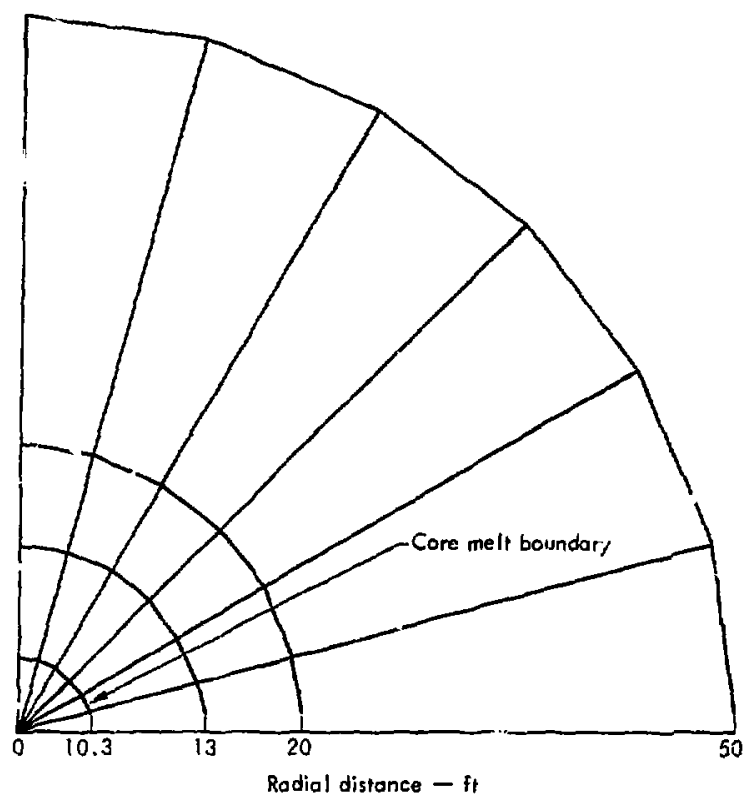

Conditions

\begin{tabular}{|c|c|c|c|c|}
\hline & Core melt & & Soil & \\
\hline$\kappa, B+u / f t \cdot h \cdot o R$ & 10.0 & $\begin{array}{l}\text { Wet } \\
1.0\end{array}$ & $\begin{array}{c}\text { Average } \\
0.75\end{array}$ & $\begin{array}{l}\text { Dry } \\
0.5\end{array}$ \\
\hline$C, 8+v / 16 \cdot{ }^{\circ} R$ & 1.12 & 0.44 & 0.35 & 0.26 \\
\hline$a, 1 b / f^{3}$ & 2.70 & 125 & 118 & 112 \\
\hline
\end{tabular}

No. of divisions in each region

$\begin{array}{cr}\text { Range, } \mathrm{ft} & \text { No. of radial } \\ 0.0 \text { to } 10.3 & 8 \\ 10.3 \text { to } 13.0 & 10 \\ 13.0 \text { to } 20.0 & 14 \\ 20.0 \text { to } 50.0 & 30\end{array}$

Fig. 3. Schematic of the element mesh for the steam generation calculation. 


\section{Results}

ONE-DIMENSIONAL LDEAL GAS

Results for the on'-dimensional, ideal-gas calculations are shown in Figs. 4 to 7 using dimensionless variables. In Fig. 4, the normalized active mass efflux, ${ }^{*} M_{O}$ is ciefined as the amount of active mass released $t s$ the atmosphere divided by the amount of inactive gas initially contained within the pores of the earth in the column. In conjunction with the dimensionless time, 7 , defineo previously in $\mathrm{Eq}$. (7), the results are universally applicable for any area or length of the columil and any porosity, permeability, or gas viscosity. Three values of containment shell pressures are shown, which should bracket expected values for most for seeable accidents.

In order to explain the use of dimensionless parameters, we shall consider the following example of axial flow in the annliar space between the cuter surface of the containment shell and the cofferdam (see Fig. 1). Since the flow is exial, we use the Cartesian coordinate results in Fig. 4.

Length $=40 \mathrm{ft}$

Arez $=\pi+\times\left(150^{2}-235^{2}\right)=3360 \mathrm{it}^{2}$

Porosity $=0,1$

Poce volume $=0,1 \times 40 \times 33 r n 1=13,400 \mathrm{st}^{3}$

$\left.P_{1}-P_{0}=i 50-14.7\right)=35.3 \mathrm{lb} \cdot \mathrm{in}^{2}$

Density it imbient conditions -0.075 it $\mathrm{ft}^{3}$

Gis u'iscosity $=5.0 \times 10^{-7} \frac{1 \mathrm{~b} \cdot \mathrm{s}}{\mathrm{ft}^{2}}$

\footnotetext{
Active mass is defined as the mass of material i ially contained in the containment $s: .$. ?.
}

$$
\begin{aligned}
& \text { Permibuhty } 0.111 \text { ing }
\end{aligned}
$$

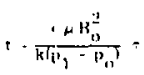

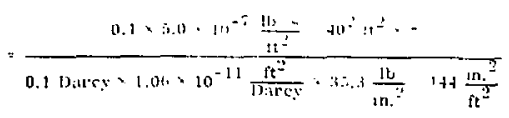

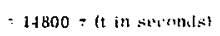

$$
\begin{aligned}
& =4.12+11 \text { in theurst }
\end{aligned}
$$

The initial mass of gas in the pores of the solid, calculated from the density at ambient conditions, is

$$
\begin{aligned}
& \mathrm{m}_{\mathrm{i}}=0.075 \frac{\mathrm{lb}}{\mathrm{ft}^{3}} \times 13,400 \mathrm{ft}^{3}=1,000 \mathrm{lb} \\
& \mathrm{m}=1000 \times \mathrm{M}_{0}(\mathrm{~m} \text { in } \mathrm{ib}) .
\end{aligned}
$$

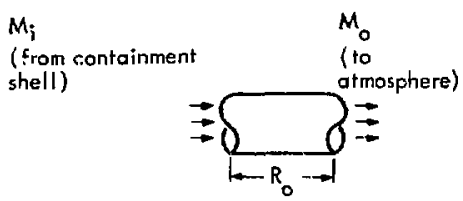

(a) Model-flow through a constant-ared porous column

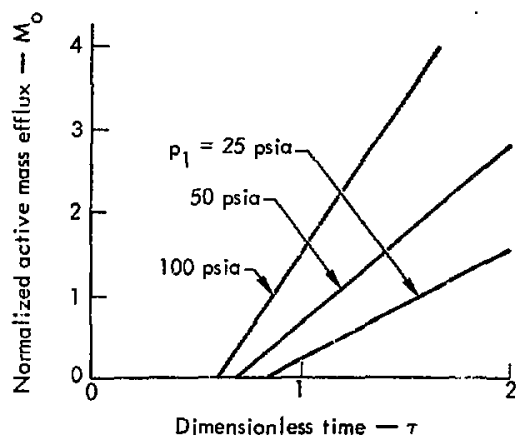

(b) Results

Fig. 4. The effect of time and pressure on the normalized active mass efflux calculated in Cirtesian coordinates for an ideal yas and for a value of po of $14.7 \mathrm{psia}$. 

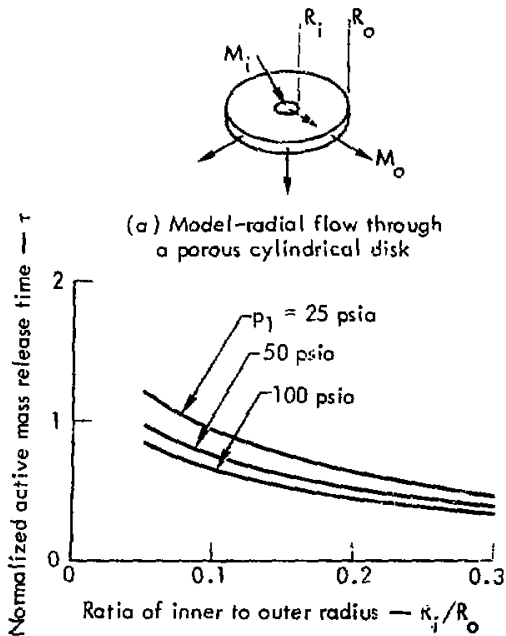

(b) Results

Fig. 5. Normalized time at which the active containment-shell gas is released at radius $R_{O}$; calculated in cylindrical coor tinates for an ideal gas and a vine of $p_{o}$ of 14,7 psia.

We conclude for this exumple that no active gas is released until $\tau=0.70$ (from Fig. 4) or $\mathrm{t}=2.88 \mathrm{~h}$. At $\tau=1.0$, or $\mathrm{t}=4.12 \mathrm{~h}$, the amount of active gas released would be $M_{0}=0.65$ or $m=650 \mathrm{lb}$. The average nowrate over this time period is $524 \mathrm{lb} / \mathrm{h}$.

Results for cylindrical coordinates where the dimensionless time for initial release of active gas to the atmosphere is plotted against the ratio of inner to outer radius are presented in Fig. 5. The radius ratio is a parameter which must be included in cylindrical and spherical coordinates since the flow area is a function of radius. As ir the case of Cartesian coordinates, there is a period of time when no active gas is released into the atmosphere. During this delay time, active gas is permeating through the solid and displacing the gas initially in the pores. The flow rate increases gradually from zero; however, by the time active gas starts to be released the flow rate is normall; substantial. Use of results from the cylindrical coordinate case would be appropriate, for example, if active gas was released inco a sand layer just beyond the :adius of the cofferdam (see F'ig. 1). Since the clay above and bolow the sand layer would prevent appreciable vertical flow, gas would permeate radially outward to a place where it could be released such as a river channel.

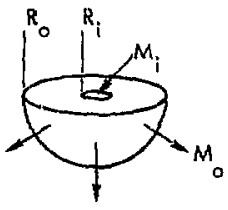

(a) Madel-radial flow through a porous sphere

I

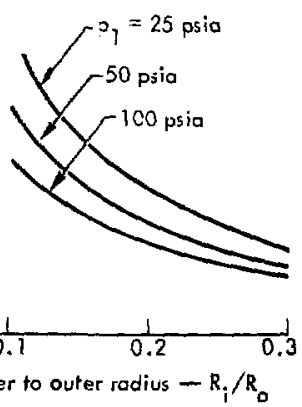

(b) Results

Fig. 6. Normalized time at which active containment-shell gas is released at radius $R_{0}$ for varying radius r.tios; calculated for a $p_{0}$ value o: 14.7 psia. 


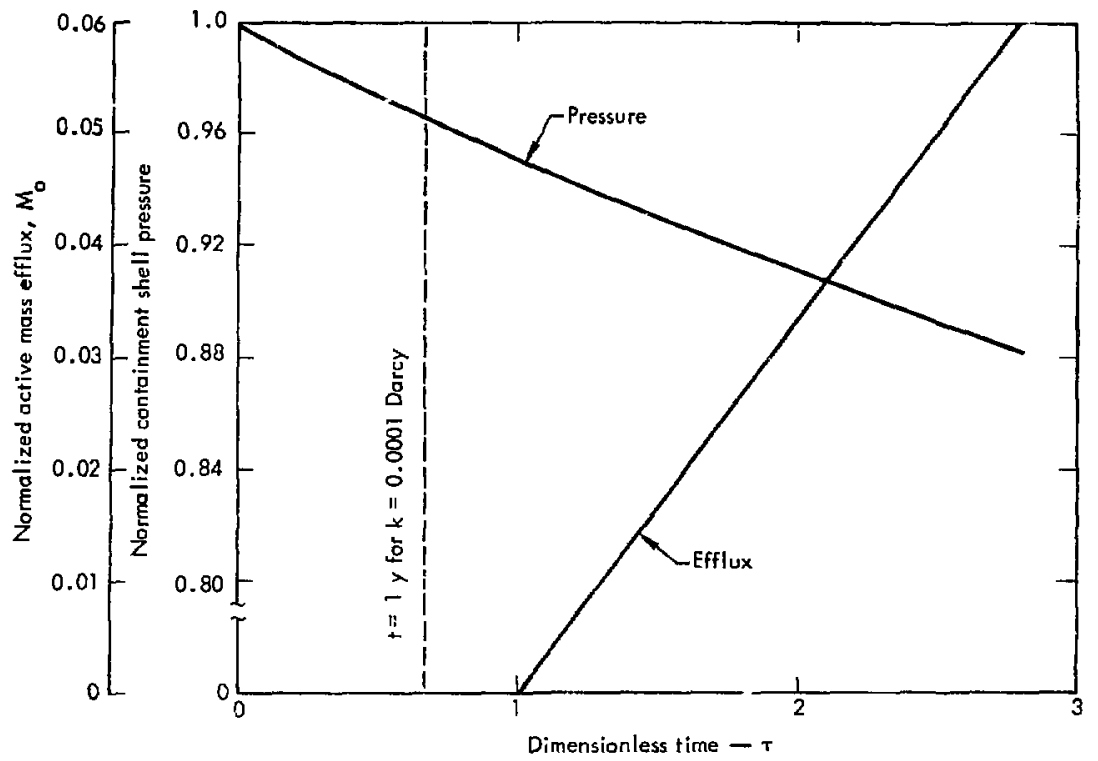

Fig. 7. Containment-shell-pressure decay and active mass efflux for core meltdown analysis; calculated in spherical coordinates for an ideal gas and the following parameters: $p_{1}=100$ psia, $c=0.08, R_{i}=15 \mathrm{ft}, R_{o}=120 \mathrm{ft}, \mu=5 \times 10^{-7} \mathrm{lb} \cdot \mathrm{s} /$ $\mathrm{ft}^{2}$, and $\mathrm{t}=1.3 \mathrm{~T} / \mathrm{k}$, where $\mathrm{t}$ is the time in hours.

The spherical coordinate results of Fig. 6 may be applied to the analysis of the flow of pressurizej gas after penetration of the containment floor. From a calculational standpoint both cases stıown in Fig. 1 are nearly identical.

In Figs. 4 to 6 , results sre presenter for a constant driving pressure. Figure 7 shows a specific case in spherical coordinates when the mass leaving the containment shell and permeating into the soil was calculated. The driving pressure in the containment shell would then decay as mass was lost to the soil. At the time active gas starts to be released from the outer boundary $(\tau=1.0)$ the driving pressure has decayed by only $5 \%$. This pressure decay would have been less if cylindrical or Cartesian coordinates were used. We felt that the use of a constant pressure, in lieu of the more accurate pressure decay, is justified since the effect of mass loss is usually small and other factors such as operation of the emergency containment cooling system are probably more dominant.

\section{ONE-DIMENSIONAL MULTIPHASE FLOW}

Two-phase flow with condensation was studied and the results are presanted in 


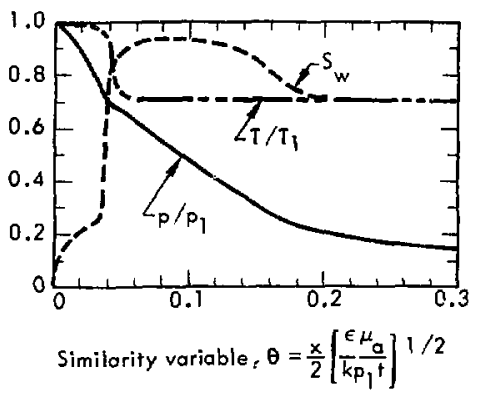

Fig. 8. Water saturation, normalized pressure, and temperature di $\varepsilon$ tribution for $p_{1}=100$ psia.

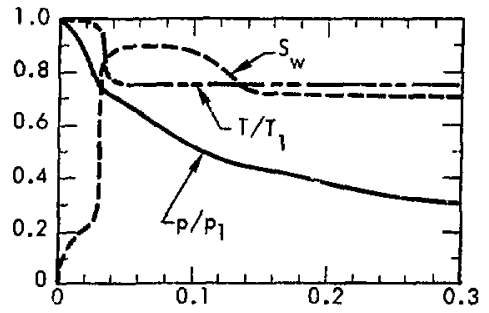

Similarity variable, $\theta=\frac{x}{2}\left[\frac{\epsilon \mu_{a}}{k_{p_{j}}^{\dagger}}\right]^{1 / 2}$

Fig. 9. Water saturation, normalized pressure, and temperature distribution for $p_{1}=50$ psia.

Figs. 8 through 11. Containment shell gas is taken to be pire saturated steam at the indicated pressure. If the containment shell pressure is held constant for example at 100 psia, the pressure, temperature, and water saturation distributions may be found for any position and time using the similarity variable $\theta$ (see Fig. 8). This similarity variable gives spatial variation for a given time where a small value of $\theta$ corresponds to positions

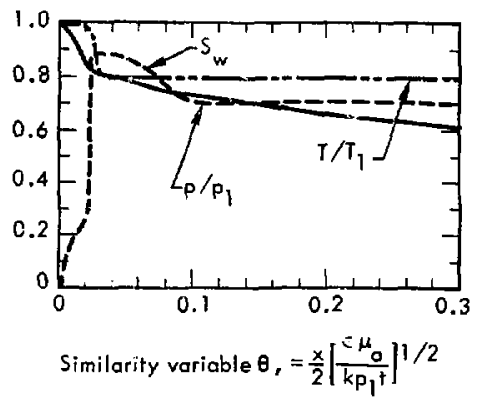

Fig. 10. Water saturation, normalized pressure, and temperature distribution for $\mathrm{p}_{1}=25$ psia.

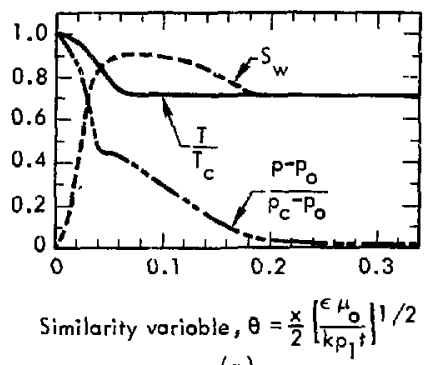

(a)

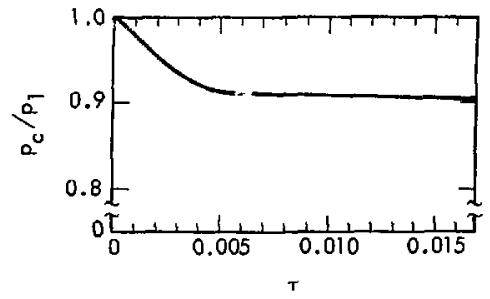

(b)

Fig. 11. Part (a) shows water saturation, normalized pressure, and normalized temperature aistribution for pressure decay for $p_{1}=100$ psia. Part (b) shows containment-she!l pressure as a function of time at $p_{1}$ $=100$ psia. 
close to the pressure source. It also gives temporal variation for a given spatial position with time increasing from right to left in the direction of decreasing $\theta$.

If we consider a given time, the interface between the soil and the cavity filled with steam is at $\theta=0$. Here, the temperature and pressure are equal to the containment shell conditions so that the normaltzed values are unity. Also the steam quality is $100 \%$ yielding a water saturation that is zero. As we focus on increasing values of $X$ (or $\theta$ ), the pressure decreases as a result of momentum loss in the pores of the solid. In this negion. $0<\theta<0.04$, the soil has been heated to the saturation temperature of the steam. The sligbtly negative slope corresponds to a decrease in saturation temperature with decreasing pressure. Steam had previously condensed to $w$ ater in raising the temperature of the soil, but no further condensation is taking place in this region. Some of this water remains in the pores resulting in an increase in $w$ ate $r$ saturation.

As $\theta$ increases just beyond 0.04, a point is reached where the soil has not yet reached the steam saturation temperature. Condensation here results in an abrupt increase in water saturation. This region is very narrow and the temperature decreases abruptly to ambient temperature.

Beyond $\theta=0.04$, the water saturation remains higher for some distance because the previously condensed water has been pushed ahead of the condensation region. Water and gas flow is nearly incompressible in this region and the pressure gradient is almost linear. For $\theta>0.2$, flow is essentially that of the gas phase alone.
The active fluid front is determined by integrating the velucity of the gaseous phase with time. For all three values of pressure examined, this interface occurred at a value of $\theta=0.05$

In comparing tine ideal gas salculation to the two-phase, condensible flow calculation in order to determine the extent of radioactive penetration, we must consider that while the total porosity of the soil is probably close to $30 \%$, the liquid fills most of the void space. If we choose the initial saturation of $70 \%$, then we should compare an ideal gas calculation with porosity of about $10 \%$ to the two-phase calculation of total porosity equal to $30 \%$. Comparing results of Figs. 4 and $\theta$ for 50 psia, we have an interface time $\tau$ and similarity variable $\theta$ of 0.70 and 0.05 respectively. Converting to a dimensional time for the ideal gas and two-phase flow cases, we have

$$
\begin{aligned}
& t_{i}=\frac{\epsilon_{i} \mu R_{o}^{2}}{k\left(p_{1}-p_{o}{ }^{\prime}\right.} T \quad \text { (ideal gas) } \\
& t_{t}=\frac{x^{2} \epsilon_{t} \mu R_{0}^{2}}{4 k p_{1} \theta^{2}} \quad \text { (two phase flow), }
\end{aligned}
$$

where as before $x=\frac{x}{R_{0}}$. We are interested in the downstream face of the column where $x=1$, so that

$$
\begin{aligned}
& \frac{t_{t}}{t_{i}}=\frac{\epsilon_{t}\left(p_{1}-p_{0}\right)}{4 \epsilon_{i} p_{1} \theta^{2} T} \\
& =\frac{0.3 \times(50-14.7) p s i a}{4 \times 0.1 \times 50 p \operatorname{psa} \times 0.05^{2} \times 0.70}=303 .
\end{aligned}
$$

In other words, the estimated time for release of active material in the two-phase, 
flow calculation is about 300 times longer than in the ideal gas approximation. These two gets of results (containment shell $\mathrm{gas}$ consisting of $100 \%$ steam or ideal gas) are bounds for release of radioactive material. Cases where mixtures of steam and ideal gas are forced through the soil would give results in between these limits.

Figures 9 and 10 show similar results for containment-shell pressures of 50 and 25 psia. Figure 11 shows containment shell pressure decay as fluid is lost into the soil. The initial containment shell pressure does not change appreciably for this case so that results are similar to those of Fig. 8. The pressure curve is normalized using the cavity pressure in all cases, but in Fig. 11 this pressure is a function of time. Temperature curves are normalized in a similar fashion.

\section{TWO-DIMENSIONAL IDEAL GAS}

We performed a two-dimensional calculation with the specific geometry shown in Fig. 2 to show effects of spatial variation in soil permeability and aspecifir werstation geometry. These calculations

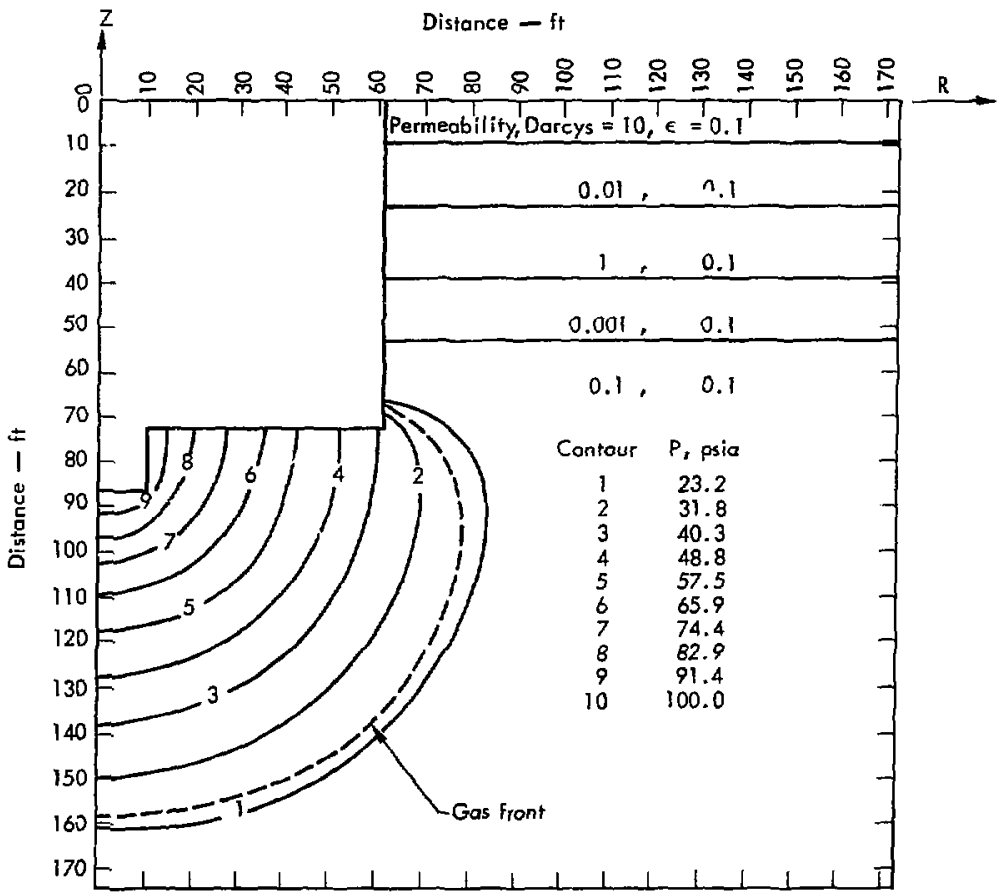

Fig. 12. Pressure profile of a two-dimensional calculation at $t=2.9 \mathrm{~h}$. 


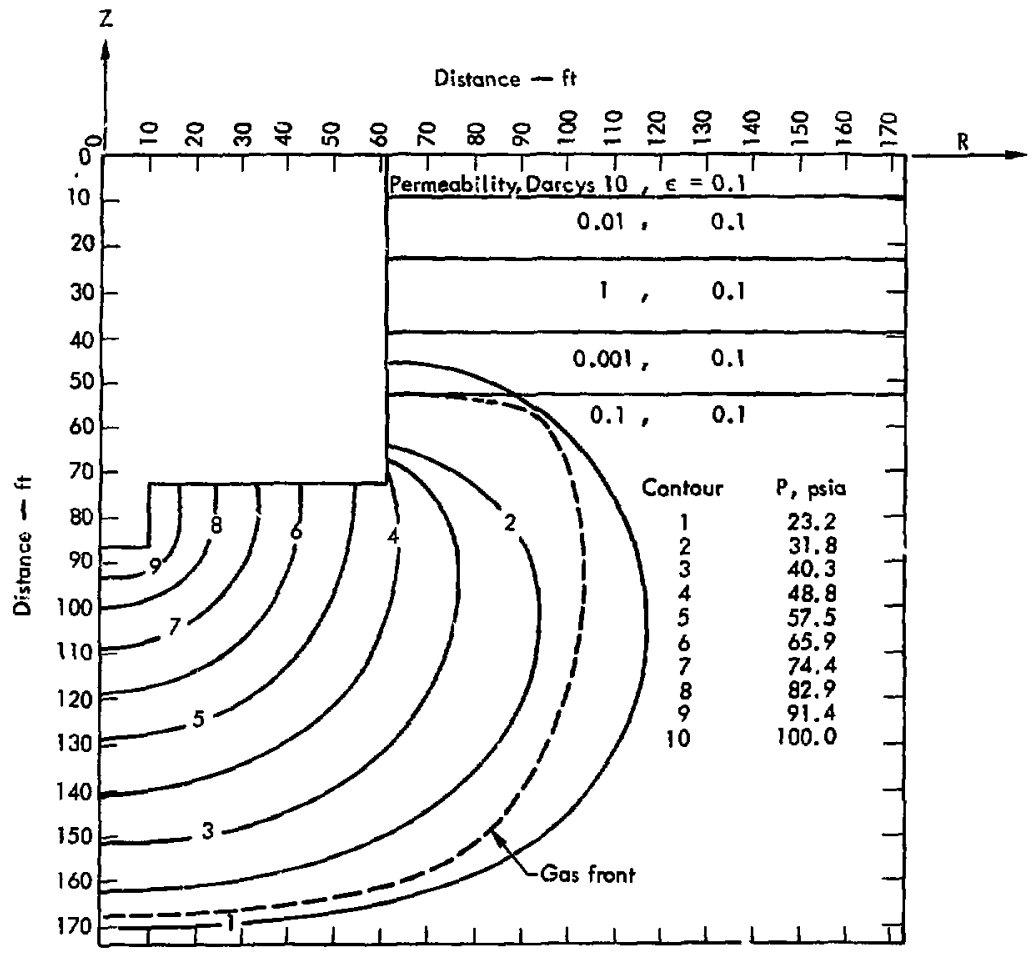

Fig. 13. Pressure profile of a two-dimensional calculation at $t=6.2 \mathrm{~h}$.

were found to be time consuming. Results in Figs. 12 to 14 show the pressure distribution and the location of the active gas front at three different times. At the later times, a deviation from the one-dimensional spherical case occurs Which delays the propagation of the active gas front. An initial value of containment shell pressure equal to 100 psia was chosen and allowed to decay as mass diffused into the soil. The change in driving pressure was negligible for this case.
Note that the permeabllity of 0.1 Darcy, which corresponds to that expected for sand, was chosen for the lower region. Had a lower value of permeability been used, results would have been similar except that propagation of the front would have taken a longer time.

\section{STEAM GENERATION BY} MOLTEN POOL

If the core melt has penetrated the containment floor (second case in Fig. 1). 


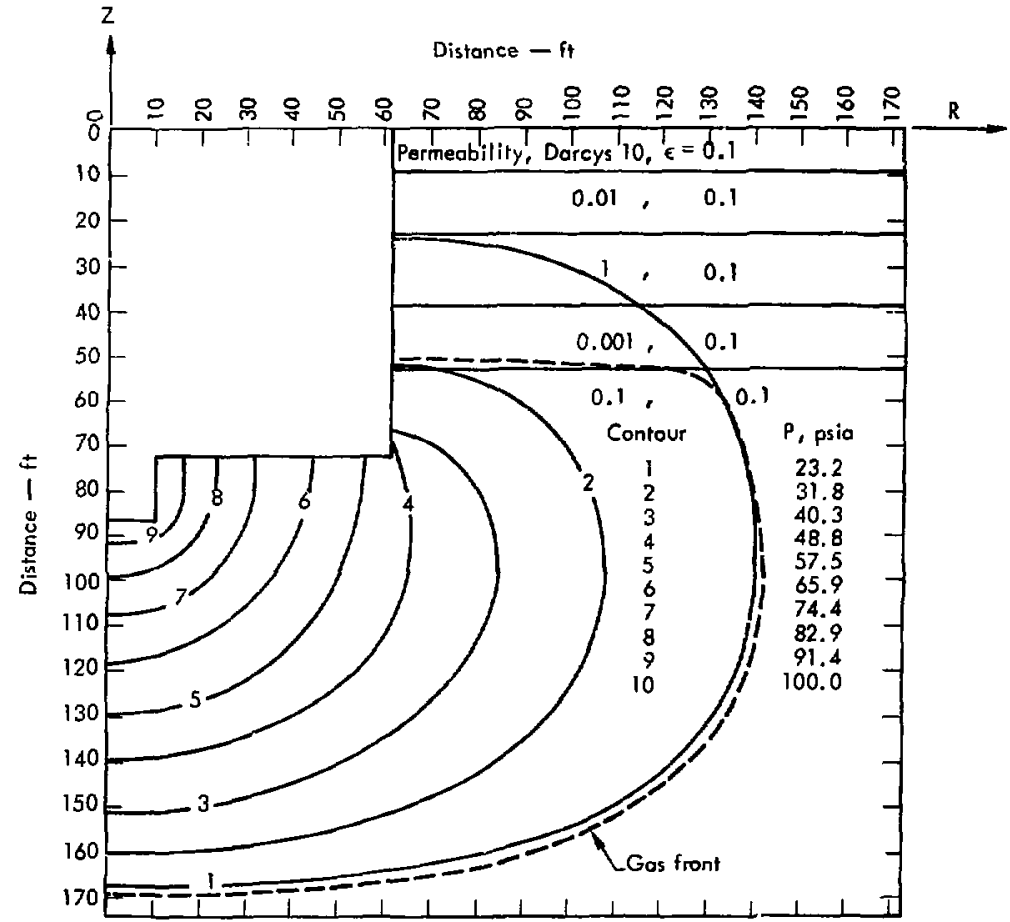

Fig. 14. Pressure profile of a two-dimensional calculation at $t=14.7 \mathrm{~h}$.

the after-heat from the reactor would vaporize the water present in the pores 0 ' the adjacent soil. This steam generation is described in Fig. 15 along with values of the quantity of steam required to pressurize a $2 \times 10^{6}-\mathrm{ft}^{3}$ containment shell to 50 and 100 psia. Although the he at generation $r$ ate was held constant at 3.5 $\times 10^{7} \mathrm{Btu} / \mathrm{h}$ in the molten pool, the steam generation rate decreases with time since heat must penetrate more and more soil before reaching an area where water saturation is still significant. Some steam is lost by now into the soil. This loss of steam is normally an insignific ant percentage of the steam generated and only becomes important if release of radioactive gases occurs within a few hours after the accident.

Heat dissipation through the containment shell into the atmosphere was found to be negligible. Some cooling system must be functioning to keep the pressure within the containment shell below its selected design or burst pressure of $\mathbf{5 0}$ or 100 psia, respectively. 



\section{Conclusions}

1) Results for constant driving pressures of 100,50 , or 25 psia show that the time required for ideal radioactive gases to reach the surface of the ground are of the order of years if soil permeabilities are near those anticipated for silty type clays (0.0001 Darcy). These release times are shortened to about $10 \mathrm{~h}$ if permeabilities expected for sand type materials (0.1 Darcy) exist.

2) Decay of the driving pressure in a typical containment shell due to leakage of gas into the soil is insignificant for most cases because of the large volume of the shell. Incorporation of a pressure decay is important for small gas source volumes or if the soil permeability is large. Other factors such as operation of various cooling systems are probarly more dominant in affecting the driving pressure.

3) An estimate of the release time for multiphase flow (injection of all steam from the containment shell) indicates that it may be over two orders of magnitude longer than that predicted with injection of ideal gas. Cases where mixtures of steam and ideal gas are forced through the soil would give results falling between thest: bouids.

4) Steam generation, which results from core snelt penetrating the containment noor, is large enough that some cooling systems must be in operation within 4 or 5 days after the accident in order to prevent overpressurization of the containment shell. Heat dissipation th. rough the containment shell to the atmosphere is negligible.

5) Examination of the permeability between a typical cofferdam and containment shell is suggested since this annular region is an era from which some radioactive material might possibly be released to the atmosphere. Results depend upon detailed knowledge of material properties and exact construction details.

6) This analysis and future studies may be used to specify materials at reactor sites yet to be built. Backfill near the reactor may be specified for optimum conditions and materials adjacent to the containment shell may be chosen to assure adequate confinement of radioactive materials.

\section{Acknowledgments}

A study such as this is most efficient if several people combine their different talents. Calculations of flow through the soil were performed by B.R. Bowman and J.H. Pitts. J. P. McKay calculated dissipation of heat through the containment shell wall to the atmosphere, organized most of the input numbers used in the cal- culations, and performed some of the computer work. R, W. Martin performed the steam generation calculation. J.E. Mellor helped with a portion of the computer work.

V. N. Karpenko, C.E. W'alter, and D. M. Norris offered suggestions for the study and reviewed the writing of the 
report. HL Lentzner edited this report and made numerous improvements to the writing.

R. Ritzman of Battelle Memorial Institute was $r \in S p$ onsible fo: the instigation of this study, formulation of the problem, and determination of the basic input parameters. He also guided our work as we progressed so that results would be of general applicability to safety analysis problems.

\section{References}

1. F. A. Morrison, Jr., Transient Gas Flow in a Porous Column, Lawrence Livermore Laboratory, Rept. UCRL-52929 (1971).

2. F. A. Morrison, Jr., Transient Multiphase Multicomponent Flow in Poroug Media, Lawrence Livermore Laboratory. Rept. UCRL-74327, Rev. 1 (1972).

3. B. R. Bowman, TWIG, A Computer Code for the Calculation of Two-Dimensional Ideal Gas Flow in Porous Media, Lawrence Livermore Laboratory, Rept. UCID-16320 (1972).

4. R. J. M. Dewiesi. Flow Through Porous Media (Academic Priss, 1968) pp. 1-6.

5. Ibld, pp. $38-82$.

6. E. L. Wilson and R. E. Nickell, "Application of the Finite Element Methoci to Heat Conduction Analysis," Nuclear Engineering and Design 4, 276 (1966).

7. J. H. Pitts, Gas Initiated Crack Propagation in a Porous Solid-A ProgresR Report, Lawrence Livermore Laboratory, Rept. UCLD-16236 (1973). 